\title{
Benefits and Disadvantages of Streaming Practices to Accommodate Students by Ability
}

\author{
Azlin Norhaini Mansor'1, Prem Prethaban Maniam², Michael C. Hunt², Mohamed Yusoff Mohd Nor ${ }^{1}$ \\ ${ }^{1}$ Universiti Kebangsaan Malaysia, Bangi, Malaysia \\ ${ }^{2}$ Open University Malaysia, Kuala Lumpur, Malaysia \\ Email: azlinmansor@ukm.edu.my
}

How to cite this paper: Mansor, A. N., Maniam, P. P., Hunt, M. C., \& Nor, M. Y. M. (2016). Benefits and Disadvantages of Streaming Practices to Accommodate Students by Ability. Creative Education, 7, 2547-2558

http://dx.doi.org/10.4236/ce.2016.717241

Received: September 27, 2016

Accepted: October 31, 2016

Published: November 3, 2016

Copyright $\odot 2016$ by authors and Scientific Research Publishing Inc. This work is licensed under the Creative Commons Attribution International License (CC BY 4.0).

http://creativecommons.org/licenses/by/4.0/

\begin{abstract}
The aim of this research is to present findings on the benefits and disadvantages of streaming practices, particularly in Malaysian schools that are recognized as an established management strategy that caters for ability differences among students in various educational settings. This study explores an application of streaming practices that engage permanent ability groupings of students into classes for the whole school year using previous year examination results as placement criteria. Implementation of streaming is still highly debated, in terms of whether streaming benefits or problematizes educational delivery, and this study conducted at three elementary schools, using interview, finds agreement from nine teachers' and ten students' perspectives that the benefits of streaming outweigh its disadvantages. Results implicate the teacher perceptions of benefits of streaming that provide for standardized lesson planning, and reduced peer pressure that facilitates students to set achievable goals and increase motivation. Disadvantages present as a rooted school culture that excludes inter-ability socialization of students according to academic ability and overemphasis on exam orientation, resulting in low self-esteem and achievement motivation. Implication of the study includes further research looking at strategies schools can employ to overcome these disadvantages.
\end{abstract}

\section{Keywords}

Class Streaming, Streaming Practices, Streaming Benefits

\section{Introduction}

The Malaysian education philosophy aims to develop the potential of individuals in a holistic and integrated manner so as to produce individuals who are intellectually, spiritually, emotionally, and physically well adjusted. Within this, policy also highlights 
that education contributes to developing pupils who are knowledgeable and competent, having high moral standards towards personal well-being, and who are responsible members of their family, society and the nation at large. Additionally, the Malaysian government has consistently initiated and moved to implement efforts to reflect growing global expectations of national educational systems (Ministry of Education, 2003).

A major element of Malaysian Government policy have been statements to reform national education to broaden opportunity towards fostering national unity and to support economic growth. Poverty reductions among citizenry and expanding opportunities and choices for students are a key area of these policies. In general, education is accepted by Malaysians as offering opportunity for upward mobility and the chance for a better life for their children; government efforts towards this provision are supported at the family level by most parents.

Large capital investment in educational infrastructure, supported by substantial recurrent expenditure since the 1970's, illustrates the government's commitment to education as a prime contributor to national development. Various programs have been implemented to meet the challenges of educational equity, curricular relevance, and the promotion of pre-school education.

The government also recognizes the presence of three types of curriculum in school environments. Firstly, the written curriculum is the knowledge, skills, and values that form the core of content, outlining what is to be taught by teachers. Secondly, the taught curriculum defines what is taught in the classroom including acquired knowledge, skills developed, and values inculcated in students. Thirdly, the examined curriculum is the knowledge, skills, and values that are tested, either in summative or in national stage examinations-the UPSR, PMR, and SPM (MOE, 2012). The written curriculum gives school management the flexibility to use local judgment and creativity to plan teaching; from this, ability grouping has emerged as a preferred organizational strategy.

Various programs were also implemented to meet challenges with respect to educational quality, curriculum relevance and the promotion of pre-school education. Under the school based management policy, more schools are given certain level of authority to plan and decide how the instructions from the ministry will be implemented. Streaming of students is one example that describes that scenario. Streaming in this study refers to ability grouping to place students in particular classes. This streaming is usually based on the students' yearly summative assessments. Thus, it has become common practice in many schools around the country to group students into classes based on their academic performance as a management strategy.

\section{Streaming Practices}

Streaming refers to the act of grouping students into classes based on their intellectual and/or academic endeavors in this study (Macqueen, 2008; Kumar, 2004). In this study, streaming refers to permanent ability grouping for the whole year, based on the students' previous year end exam results. The students who are grouped such ways usually 
remain in the particular groups till the end of the primary school years, or they might change classes depending on their next year-end assessment. Macqueen, in her study describes the term "streaming" as the practice of allocating students to homogenous achievement classes based on some measure of each student's overall academic performance. She further added that such practices became a popular method of allocating students to classes in larger schools after the introduction of standardized testing in the 1920s. However she also stressed that the practice can be traced back to the 1800s.

Streaming has long been associated with disadvantaging students in lower ability groups since its inception following the 1931 Primary School Report (Ollerton, 2002). Streaming is also associated with exclusive labelling in academic and social terms (Kulik, 1992). Statistics consistently produce strong disparity in attainment scores between one "high ability" group and 'lower ability' groups where by lower ability groups usually score poorly in the Primary School Achievement Test (MOE, 2012). Further, streaming has been found to produce different affect towards students' academic achievement and to a certain extent mentioned as being unjust (Kilgour, 2007; Liu, 2009; Marks, 2011; Page, 2001; Pare, 2004; Rudowicz, 2003; Smith, 2011; Md Nor et al., 1998; Dukmak, 2009; Adam Gamoran, 1995). Based on our experiences, both as practitioners as well as researchers, we have personally encounter how streaming has actually produced annually one high ability group and about two to three lower ability groups in a particular school.

Most primary schools in Malaysia practice streaming beginning from the time students come into the school in their Year One, which is after a month or two in their Year 1, students are assessed and grouped into classes. This move is practiced by most schools as their strategy to create the best learning experience for the students according to their ability. Today, such streaming has become very popular and widely used although there are voice against the decision to do so. Debates on the benefits and disadvantages of streaming have never put to rest and the researchers have continued to study the practice because they believe it has great impact on the students' outcome.

In the Malaysian context, streaming students in their first year on exams conducted in the second month is an impossible challenge to students who have had no preschooling, and this does not reflect the National Philosophy democratically. However, the streaming philosophy cannot be dismissed considering the benefits of readiness for collaborative work, focused lesson planning per specific group learning, and associated learning motivation.

The purpose of this research into streaming (or "ability grouping") is to present identify benefits and disadvantages of streaming practices particularly in the Malaysian Primary school context. The aim is to look at teacher and student perspectives to assess and determine how streaming helps or hinders improvements in teaching and learning in experiential terms from the unique context of the Malaysian Primary setting.

\section{Methodology}

The research adopts a qualitative research approach to accommodate the researcher as 
the primary instrument for data collection and data analysis (Merriam, 2007), being able to engage responsively in adaptive ways fitting the social and experiential nature of the research aims. Semi-structured interviews supported by questionnaire with interview formed the data gathering method. Validity and reliability checks involved member checks, peer review and documents from audit trails.

The findings of the study comprise the opinions of the participants from three Primary schools located in a suburban area chosen for accessibility to the sample population. From each school, respondents were selected by role to include one teacher of English, the "Head of Panel" for English (Subject head), one school senior assistant for Curriculum, and 10 students (five from each ability group). The 10 students from each school were selected from 2 different group-high ability and low ability. Overall, a total of 9 teachers' and 30 students were interviewed.

A set of semi-structured questionnaire were used to obtain information about the thoughts, feelings, attitudes, beliefs, values, perceptions, personality, and behavioral intentions of the research participants. Interviews were conducted to gain a review of the teacher's perception of his/her lesson in terms of strengths and weaknesses. All interviews were videotaped in order to assist the researcher in review and validity, to avoid misinterpretation. Their opinion on the subject has been grouped according to the research questions (themes) and presented as below:

1) Benefits of streaming

2) Disadvantages of streaming

Fictitious name are used to represent teachers, whilst students are labelled as Lily 1 to 30.

\section{Findings}

\subsection{The Benefits of Streaming}

Overall, streaming implementation in schools is seen beneficially, sourced from the various perspectives in this study. In general, the senior assistants view streaming as a school management strategy that supports a good quality education in line with the school objective. English panel heads and the teachers find it to be a systematic approach that enable them perform well as effective teachers.

All three interviewees were of the opinion that streaming had advantages in the teaching and learning process. A number of reasons were given including lesson preparation that focused group needs of streamed groups that have been streamed as opposed to unstreamed mixed ability groups. Responses given include the following:

....the first thing I always do when I am given a new class is try to understand the students in a few different aspects... past result, ability to interact, vocabulary and any other information related to their ability... it will give rough idea on what would be best for them.... even the material I relate to them during lesson will be a mixed idea about what they know... usually students of a particular group have particular interest... this will allow me plan lessons with elements that will interest 
the group...

\section{Daffodil}

...streaming is our way to group students according to their capability... we believe different capability would mean the students have different need... training them according to their strength and weakness will enable them to construct knowledge effectively...

Rose

The curriculum requires teachers to move towards student centered learning from the traditional teacher centered learning... However we still use both in our teaching... Actually the $4 M$ students are exposed to student centered learning... whereas $4 R$ students require more direct instructions... which is very much teacher centered learning... Streaming has made teachers more prepared to teach effectively... Teachers become more skillful in handling a particular group of students in the time allocated in the time table...

\section{Sunflower}

Although generally, there was a common opinion that moves towards streaming were good, Daffodil also raised concern show $4 \mathrm{R}$ students would learn at a slower phase. However, she added that streaming has helped her to be more prepared for the two classes as she planned lessons according to needs. Her response was as follows:

$4 M$ students have better command of English language compared to $4 R$... so $4 M$ students perform better and usually have greater expectations... So I also give $4 M$ students projects and homework that are more challenging that meet their need... task that trigger higher thinking order is given here... but when I teach $4 R, I$ will have to give more instructions and more examples to them so that they are able to respond well to my teaching... a little time consuming at times... but as they catch up the time factor could be improved...

\section{Daffodil}

From a management point of view, Gladiolus pointed out that streaming had been a "holistic" approach for the school in improving educational standards and educating processes. According to her, since streaming began, management had been able to formulate correct ideas and approaches to improve educational standards by providing the necessary learning opportunities and experiences effective to the differently streamed groups. This practice, in her perspective, has become favorable to the school towards achieving the desired progress over a number of years. In terms of improving educational processes, Gladiolus claims that streaming students in different groups created equal opportunity for all classes of students to participate in class and co-curriculum activities.

We could actually target better results in the Ujian Penilaian Sekolah Rendah (UPSR) and achieve with high accuracy by providing the assistance and training needed by streamed classes.., we monitor instructions and lessons conducted in these classes... with years of streaming students we believe our teachers have ac- 
quired the experience to teach ability classes... but if we didn't group them we can't even make inference to plan the best teaching... and in a mix group the challenges can continuously change...

Gladiolus

Coxcomb and Gladiolus had similar points of view in the way streaming helps school improve education standards. Further, Coxcomb also pointed out that streaming students helps the school plan remedial education, thus:

The school will be able to plan remedial classes for the weaker students and where the smarter students are concern... we will know how many will be able to achieve the school target... at the end of the day its results that is seen... Actually because of streaming the school will be more alert on what is happening academically... the group of classes are some way or other a fraction to tell us the rate of success and failure earlier... More like a forecast.

Coxcomb

Aster pointed out that streaming students has allowed the school to be able to manage its resources more effectively. According to Aster the school allocates special funds to buy specific reading materials and work books to equip students with the necessary, personalized support because the type and quantity of support materials are determined based on varying group needs. In this way, the material for the higher ability group usually differs from the lower ability group.

Planning is a very important due to the limited resources we have in government schools... it is best we stream students and understand their collective needs. Even the reading and workbooks we provide them is based on the group needs. Even teachers have different expertise and capabilities... Understanding of mother tongue will be helpful in teaching the weaker class... its productive for the management to achieve the desired result...

Aster

Almost all $4 \mathrm{M}$ students come from well to do families, ...their parents always follow up with the children's progress and give the necessary support... including materials, tuitions... but the $4 R$ students are not lucky in that sense. Whatever the school provides is what they get... we try our best to arrange whatever is within our reach and provide based on their need...

Gerbera

All the interviewees generally agreed that there are various advantages in streaming for teachers, students and the school. Their statements were contrasted and compared with student interviews. The higher ability students' statements seem to indicate that being in a streamed class is a positive and beneficial idea. Their responses are as follows:

We are proud to be in $4 M . .$. friends... parents always tell I must be in best class... 
Teachers and friends will say I am smart. My parents happy... will buy gifts for me...

Lily 2

My class is the best class and only the good students study in this class.

Usually only students from our class score lots of $A s^{\prime}$ in exams...

Lily 4

\subsection{Disadvantages of Streaming}

Segregating students and categorizing them based on academic performance had a number of common complaints voiced by the teachers. The most common reason given was that the better performing $4 \mathrm{M}$ class, had advantages over the weaker $4 \mathrm{R}$ class who always needed more time and help. In response to the question, "What were the disadvantages of practicing streaming in school?" teachers constantly voiced concerns on the issue of students' behavioral issues. Some of the responses are quoted below:

Our intension is clear... streaming is to teach students based on ability level and provide necessary support but there are always other challenges we have to face due to streaming. There is always complaints from parents that a double standard practice... teachers are accused of paying less attention to the lower ability groups...

Hibiscus

Parents, especially of the lower ability group are quite quick at attacking the school... a common accusation is school is concentrating on the higher ability groups only to achieve more number of straight $A s$ '... but this is very untrue... that is never our intention... sadly many parents of these children don't monitor their children's at home... but when results are out... they are quick to blame teachers and this grouping practices...

Rose

Complaints are always there from lower ability group parents... some would approach us to place their children in the higher ability group... we try to explain that streaming is done to help their children and not penalize them for achieving lesser in exams. Placing them in low ability group will allow them to get the extra help they need.

Sunflower

Challenges that schools face from certain parents because of implementing streaming is an ongoing issue, however, streaming is practiced by schools because they believe it is the best strategy to effect positive teaching practice. This said, all three interviewees agreed that streaming does create a poor impression for students in lower streamed groups. Following are some of the opinions given:

Many students in the low ability group exhibit low self-esteem and motivation. Some feel that only the smarter classes or higher ability group are capable in studies and don't make to improve in their studies... just because they are sitting in 
the lower ability classes...

Daffodil

Student will always compare each other. We try to motivate the lower ability group to do better by asking them to study hard and get promoted to higher ability classes, but some students in the lower ability look at this negatively... they think they belong to the lower ability group because they are there too long and never got a chance to enter a higher ability group... and lost self-confidence.

Coxcomb

Streaming is not a branding process... it is not to group the cream among the cream and dump the poorly performing students... but students in the lower ability group have the tendency to mix within their group and behave antisocial towards the higher ability group...

Gladiolus

Teachers' opinion seems to be supported by student statements. Lower ability group students' statement regarding perceptions of the $4 \mathrm{M}$ classes indicates low confidence and lack of motivation. Streaming has made many of the lower ability group feel inferior and damaged their confidence to excel academically. Following are some of the opinion of the lower ability class students:

My parents and teachers always ask me to study hard to get chance to study in 4 M... I can' t... very difficult... $4 M$ students very clever...

Maple 1

I can't study like them... they go for tuition...

Maple 2

Teacher always choose $4 M$ students because they are clever.

Maple 3

Our class students don't go to $4 M$ class... the students there don't like to mix with us...

Maple 4

I tried to study... but not as good as them... 4M students always best...

Maple 5

These statements seem to suggest that lower ability students' fail to get peer support from higher ability students. If motivation and self-esteem has been damaged, opportunities for lower ability groups will continuously decrease. Streaming is also expressed as an antisocial tool that doesn't encourage students to mix, which does not reflect the expectations of real life situations that involve socialization that don't recognize ability. Following are some of the comments given by the teachers:

It is a sad scenario to see children study in the same school yet don't mix around freely... although it's not the school s intention to do so... but I have to see that it is like a side effect of streaming...

Aster

It is normal for students to have their own circle of friends... what more when they 
study and spend time together at least 6 hours a day... so when they are streamed according to a certain group, they don't really get a chance to mix around... smart one's with only the smart ones and weak ones with only the weak ones.

We are aware that students tend to keep within their class. Recess is the time they meet... as teachers, we do try to balance by creating opportunities for all the student to mix around without limiting themselves to only their classmates... like during co curriculum activities... but the time for this is limited...

Gerbera

During class observation, it is obvious the teacher's teaching is distracted due to attending discipline problems. This is a challenge the teacher had to face in the main in lower ability groups. It seemed like these challenges are related to streaming. Following are the teacher's statement regarding this:

It is challenging to get a hundred percent attention from the lower ability group. There are many reasons for this like students poor command of language, lack of motivation... I have to agree that placing all the lower ability students in one class is a challenge teachers have to face. These problems are minimal in the higher ability group...

Coxcomb

Discipline issues are common in schools and quite obvious in the lower ability group the moment we stream these students... this sort of problem is anticipated...

Gladiolus

The teacher's opinion was supported by the finding from the students. Following are the statements of the lower ability group students;

English difficult... class noisy... students like to fight... teacher punish. Difficult to get high marks.

Maple 7

Classmates always noisy when teacher not in class... when teacher teach... they like to talk...disturb other student... quiet if teacher scold.

Maple 5

Higher ability students are reported as better behaved. Teaching went on smoothly in this class. Following are some of the opinions of the higher ability class students:

Our class students are very discipline... we don't talk when teacher is teaching... Even when teacher is not in class we have things to do...

Many prefects and librarians in our class... we don't fight like the weaker classes.

Our class is nice to study... Teachers like to teach... we also love our teachers...

The $4 M$ students usually keep forwarding questions till they understand... there is 
always high competition there... but the $4 R$ students will usually depend on my instruction on what to do next...

Calla

$4 M$ students have better command of English language compared to $4 R$... so when I teach $4 R I$ will have to give more instructions and more examples for them to be able to respond well to my teaching... a little time consuming of course... at times they will be left behind when it comes to completing lesson as planned...

Hibiscus

The students too voice disadvantages of streaming in terms of competition in the good class and discipline problems especially in the weak class. These are some of their opinion:

High competition... all the students are smart..Sometimes argue with my classmates.

Lily 4

It was noted that teachers, when teaching English in weaker classes will resort to using Bahasa Malaysia (BM) to ensure that weaker class students understand what is being taught. Teachers too have to deal with discipline issues which were higher in the weaker class.

\section{Discussions}

The main finding of the study seem to evidence effects of streaming practices in the current schools' set up, a limitation is that this is restricted to English teaching, which excludes differing subject teaching approaches and syllabi.

The study suggests that streaming can be beneficial in conditions where students exhibit differing abilities in the command of language, particularly in vocabulary, sentence building, tense usage and etc. When students are placed in mixed groups, entry level ability testing is a huge challenge, even prior to the challenges of individuated lesson planning. In situations where students are placed in mixed ability groups, teachers' obligations to successfully differentiate may affect the level of engagement and motivation of both higher and lower ability students.

Streaming students into groups also seems beneficial in planning terms with respect to teacher time management. In consideration of the limited time that a teacher may have, approximately 40 minutes for each lesson, appropriate instructions according specific groups could avoid lengthy explanations that could reflect badly in the learning process.

Interestingly, in the research contexts, streaming has allowed the school to provide more personalized support to lower ability groups. The school has smaller groups of lower ability students in each class compared to larger number of students in higher ability classes. This move seems to allow teachers to give better attention and support to lower ability groups as the number of students here are comparatively low. Moreover, higher ability groups may exhibit higher independence and thus require less indivi- 
duated support. Allocating more classes of lower ability groups compared to higher ability groups in this context has become a factor that contributes to making a streaming approach more efficient.

Overall students' opinions regarding the effect of streaming seem to come with mixed feeling. Higher ability students exhibit high level of self-esteem and confidence compared to the opposite in lower ability groups, both groups relate this perception to membership of the stream they belong to. Streaming has therefore contributed to inter-group comparison that works in favour of the higher ability group.

Additionally, streaming has limited the amount of peer support that lower ability students can receive if placed in a mixed-ability groups. In mixed-ability groups more able students can play a "More Knowledgeable Other" role, providing peer support for other students. In streamed classes, this peer support is not possible. From student commentary, streaming has also facilitated social mobility comparisons. Higher ability students use upward comparison to motivate themselves to improve, especially when their performance trends negatively; contrastingly, upward comparison among loweragainst higher-ability groups results in many lower ability students to experience inferiority.

Social comparisons also built division among the high- and low-ability groups, illustrated most strongly in socialization preference. Lower ability groups don't feel welcome in the higher ability group classes and this felt superiority of higher ability group students is defended by them.

Another expressed disadvantage of streaming is the claim that teachers prepare easier tasks for lower ability groups. According to the teachers interviewed, less challenging tasks are prepared for lower ability groups to match their perceived needs. However, less challenging tasks can be interpreted as giving lower attention to realistic learning needs, especially in the context of year-end examinations, explaining poor performance in these examinations which implicates permanent membership to the lower ability group.

\section{Conclusion}

As to conclude, most of the response and finding seem to suggest that streaming is more beneficial. Although there are a few disadvantages, the respondents are quite positive that it could be overcome. Using proper strategies by understanding and manipulating the relevant factors, they believe streaming could be fine-tuned to achieve the desired outcome. However, more investigations should be carried out to analyze whether this streaming practice we have in many schools in our country is best made compulsory in all schools with the necessary improvement or taken away. Investigation should also be carried out to find out whether teachers are equipped with the skills or trained to cater for the streamed classes they are designated. At the end of the day, the education system is made to educate the people in the most educated way as to ensure that education is productive in producing the citizens with great potential and integrity, so its best standardized and clear instruction on the issue is introduced in our country. 


\section{References}

Adam Gamoran, M. N. (1995). An Organizational Analysis of the Effects of Ability Grouping. American Educational Research Journal, 32, 687-715. http://dx.doi.org/10.3102/00028312032004687

Dukmak, D. (2009). Ability Grouping and Teacher-Students Interaction among High and Low Achieving Students in Middle Primary Schools in the United Arab Emirates. Journal of Faculty of Education UAEU, 26, 1-30.

Kilgour, P. W. (2007). Student, Teacher and Parent Perceptions of Classroom Environments in Streamed and Unstreamed Mathematics Classrooms. Unpublished Doctor of Mathematics Education Thesis, Bentley, WA: Curtin University of Technology.

Kulik, J. A. (1992). An Analysis of the Research on Ability Grouping: Historical and Contemporary Perspectives. Storrs: The National Research Center on the Gifted and Talented, University of Connecticut.

Kumar, P. A. (2004). Ability Grouping and Academic Achievement. Masalah Pendidikan Jilid, 27, 109-118.

Liu, H. J. (2009). Exploring Changes in Academic Self-Concept in Ability-Grouped English Classes. Chang Gung Journal of Humanities and Social Sciences, 2, 411-432.

Macqueen, S. (2008). Between-Class Achievement Grouping for Literacy and Numeracy: Academic Outcomes for Primary Students. In: Proceedings of AARE 2008 Conference (pp. 1-12). Brisbane, QLD: University of Technology.

Marks, R. (2011). Ability in Primary Mathematics Education: Patterns and Implications. Proceedings of the British Society for Research into Learning Mathematics, 31, 91-96. http://dx.doi.org/10.1080/14794802.2011.624753

Md Nor, S. et al. (1998). Struggling Students in Low Ability Grouped Classrooms: Standardized Assessments and the Uphill Battle. The International Journal of Learning, 14, 9-22.

Merriam, S. (2007). Qualitative Research and Case Study: Application in Education. Revised and Expanded from Case Study Research in Education.

Ministry of Education (2003). Curriculum Specifications for English. Putrajaya: MOE.

MOE (2012). Malaysian Education Blueprint 2013-2015. Putrajaya: Ministry of Education.

Ollerton, K. M. (2002). Grouping Patterns in Primary Schools. Mathematics in School, 31, 2-7.

Page, D. N. (2001). School Choice and the Distributional Effects of Ability. Journal of Urban Economics, 51, 497-514.

Pare, V. (2004). Exploring the Conflicts Involved with Ability Grouping. University of Connecticut: Institute of Education Sciences or the U.S. Department of Education.

Rudowicz, C. K. C. (2003). Academic Outcomes of Ability Grouping among Junior High Schools Students in Hong Kong. The Journal of Education, 96, 241-254.

Smith, C. (2011). "Ability” in Primary Mathematics Education: Patterns and Implications. Proceedings of the British Society for Research into Learning Mathematics, 31, 91-97. 
Submit or recommend next manuscript to SCIRP and we will provide best service for you:

Accepting pre-submission inquiries through Email, Facebook, LinkedIn, Twitter, etc. A wide selection of journals (inclusive of 9 subjects, more than 200 journals)

Providing 24-hour high-quality service

User-friendly online submission system

Fair and swift peer-review system

Efficient typesetting and proofreading procedure

Display of the result of downloads and visits, as well as the number of cited articles

Maximum dissemination of your research work

Submit your manuscript at: http://papersubmission.scirp.org/

Or contact ce@scirp.org 